\title{
The Consequences of the Covid-19 Pandemic for the Kazakhstani Economy and the Development of Business Strategies to Overcome Them
}

\author{
Zhanbayev R. A. ${ }^{1 *}$ Sagintayeva S. ${ }^{1}$ Temirbaeva G. R. ${ }^{2}$
}

\author{
Abildina A. Sh. ${ }^{1}$ Turovskaya M.S. ${ }^{3}$ \\ ${ }^{1}$ Almaty University of Power Engineering and Telecommunications named after Gumarbek Daukeev, Almaty, Republic \\ of Kazakhstan \\ ${ }^{2}$ Zhezkazgan University named after O.A. Baykonurova, Zhezkazgan, Republic of Kazakhstan \\ ${ }^{3}$ University associated with the Interparliamentary Assembly of the Eurasian Economic Community, St. Petersburg, \\ Russia \\ *Corresponding author. Email: zhanbayevrinat@gmail.com
}

\begin{abstract}
The COVID-19 Coronavirus Pandemic, occurring on a global scale, has quite serious negative consequences for the economies of all countries. Kazakhstan's economy is also experiencing the negative consequences of forced quarantine measures, which has created an entirely new situation of characteristic economic recession, which is a serious challenge not only to governments but also to economic science. The article considers factors that have a significant impact on social and economic stability. Preventive measures to stabilise the economy and reorient business strategies to take account of new challenges are necessary to ensure this stability. The article is devoted to the problem of finding ways to manage the economy during the crisis, focused on the point impact of state regulation measures, and new strategic approaches in business. The article is several in-depth studies and publications of the authors on the problem of finding ways of economic stabilization in the regions of Kazakhstan. Priority measures of state support of business-oriented to the use of non-financial instruments are proposed, the priority of preservation and possibility of further recovery of small and medium businesses that will have an adequate impact on consumption level is justified. Several business strategies have been proposed to address this challenge during the pandemic. Their particular feature is that they provide an opportunity to prepare for business recovery in previous forms and volumes.
\end{abstract}

Keywords: crisis, pandemic, consequences, business strategies, government support, economic recession, stabilisation, means of response, macroeconomic indicators, economic sphere

\section{INTRODUCTION}

Today, it is a fact that the COVID-19 coronavirus pandemic that has taken place on a global scale has serious negative consequences for the economies of all countries. Kazakhstan's economy is also experiencing the negative consequences of forced quarantine measures. The economic situation in Kazakhstan is affected by several factors, including falling oil prices, weakening national currencies, and the pandemic.

All of these factors have created a completely new situation of characteristic economic recession, which is a serious challenge not only to the governments of different countries but also to economic science. What is quite interesting here is that world economic experts have been forecasting the global economic crisis since 2015 [1]. However, it was not predicted that the main cause of the crisis would be a pandemic. This factor has a major impact on the analysis of the consequences, the nature and main definition of the means of response. Coronavirus infection was identified as the cause of the current crisis in the economies of various countries, rather than the increasing monopolisation of the world economy as expected. The social and economic component of global social development is taking the brunt. It has come to the fore and is the main problem for the economies of all countries. Experts estimate that the gross domestic product of Kazakhstan fell by 1.7 per cent in the first five months of 2020. By the end of the year, the government promises a more optimistic forecast, i.e. the GDP decline should amount to "only" 0.9 per cent [2]. For Kazakhstan's economy, energy prices on the global market are of paramount importance and have been primarily affected by the pandemic.

Of course, it is clear to everyone that the world economic space will not be the same after the pandemic. Of course, for an economy that is on the "oil needle", the world prices 
of oil and petroleum products are of particular importance [3].

Prices on commodity markets have shown the strongest fall since the 1990s. As a result, the oil industry, which is known to shape the country's economy to this day, will be severely affected: 15 per cent of GDP is generated by the oil and gas sector, according to the $\mathrm{S} \& \mathrm{P}$ rating agency. Exports in January-May fell by 5.5 per cent year on year, but the trade balance avoided a deterioration due to a 9.3 per cent fall in imports. Moreover, oil exports increased by 14 per cent, which sources claim was due to previous contracts [4].

\section{METHODS AND MATERIALS}

Empirical general scientific methods of knowledge have been used to study the impact of the pandemic on the economy of Kazakhstan. The method of observation and fact-finding has been applied in the analysis of the current state of the economy and identification of existing problems, identification of appropriate measures to overcome these consequences.

The modelling method is based on the study of socioeconomic phenomena using models. It has a particularly tangible effect when a multi-factor approach is used to create a system of state support measures for business during a pandemic. The application of modeling technologies makes it possible to make adequate adjustments to the mechanism for managing the increase in the efficiency of state regulation during a crisis period. The use of the analysis and synthesis method makes it possible to analyse various individual factors that affect economic, social, environmental, and other components of society's sustainable development.

In order to find and identify measures that stabilise the economy during a pandemic, a scenario method is used, which makes it possible to identify the key factors that affect the standard of living and quality of life of the population during a given period. This method involves analysing and evaluating each option, studying its structural characteristics, and possible consequences in its implementation.

\section{RESULTS}

First of all, we will focus on the negative consequences of the pandemic. This is, as mentioned above, a drop in GDP, a budget deficit, and the subsequent decline in living standards, as the state will not be able to implement social policy in the same amount. Thus, the negative effect was caused primarily by a decrease in macroeconomic indicators, such as the demand of households and business entities, a decrease in the workload of companies' production potential, real income, and employment. A new factor that has emerged as a result of quarantine measures must also be taken into account is a decline in population mobility, which will weaken the mechanisms for self- regulation of the effective distribution and redistribution of all types of resources within the country. This is already a factor in the imbalance of the state's economic system.

Besides, the predicted weakening of domestic demand and lower price growth in the main trading partner countries will have a significant disinflationary effect. The greatest impact of these factors is expected in 2021, which will lead to a significant slowdown in inflation in most of the EDB member countries and may lead to a relaxation of monetary policy [5].

The level of impact of the negative consequences of the pandemic on the Kazakh economy requires a separate and serious study. At this stage, we will use statistics and data from the Ministry of National Economy and the National Bank to identify approaches to stabilising and gradually moving the economy out of a crisis.

According to the Ministry of National Economy and the National Bank, there is currently a 4.1 per cent increase in the production of goods in the country's economy. Moreover, it is ensured by a 4.8 per cent growth rate in the manufacturing industry. Unfortunately, there has been a decline in industrial production growth rates in the first half of 2020 from 5.8 per cent to 3.1 per cent.

The information and communications sector also posted positive growth rates of 9 per cent and mining of 2.2 per cent. These agencies forecast that GDP will continue to decline in the future due to the factors that have determined the decline in the economy since the beginning of the pandemic such as domestic demand and net exports, which is shown in Figure 1.

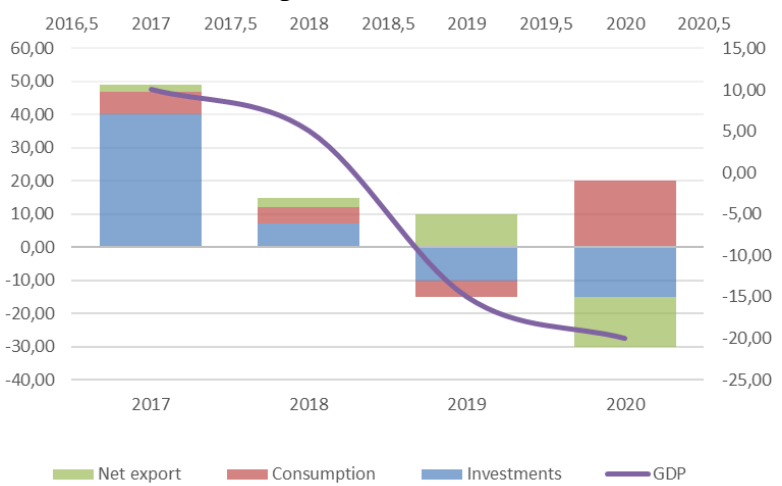

Figure 1 Dynamics of demand components

The service sector is known to be the most contact area for the risk of infection spreading. Retail trade volumes, for example, decreased by 12.6 per cent. As a result, this will lead to a decrease in household demand, which is already a macroeconomic destabilisation factor in total demand.

The next indicator to be analysed is the business activity index, which was significantly affected by the level of capacity utilisation. Trade, services, and transport sectors provide a decrease in the business activity index. In terms of capacity utilisation, approximately 20 per cent of mining companies had a capacity utilisation rate of 90 per cent and 7 per cent of construction companies had a capacity utilisation rate. 
All of these factors, which characterise the impact of the pandemic on the economy of Kazakhstan, respectively, have led to changes in investment and consumption [6].

There has been a decline in foreign investment inflows and a slowdown in domestic investment activity. It should be noted that the economy has not had time to react negatively in all areas of investment. In sectors such as construction and major repairs, there has been a 28 per cent increase, while investment in machinery and equipment has declined [7]. The volatility of the exchange rate of tenge and inflation objectively had an adequate negative impact on such indicators as income, wages and employment of citizens. Only employment statistics provide a picture that suggests some concern. Thus, in May the number of unemployed, according to the Ministry of Labour and Social Protection, increased to 1.45 million people from 442,400 at the end of March. Unemployment is expected to increase to 1 million people by the beginning of the third quarter.

The National Bank forecasts a decrease in wages in the real sector of the economy. Accordingly, the highest reduction in consumption will occur in the second half of 2020.

Thus, the above factors confirm the overall negative outlook for the country's economy and the state of crisis, although at an early stage. All this will have an impact on the state of the national budget. At the end of the first quarter, the deficit amounted to KZT 632.9 billion, which increased by 2.2 times compared to the same period in 2019. Excluding proceeds from oil sales, the deficit amounted to 1.4 trillion KZT or 10.8 per cent of GDP, which is 41.2 per cent more compared to the same period in 2019. The World Bank predicts that by December 2020 the deficit will increase to 13.2 per cent of GDP, while government debt will increase by 26.9 per cent and the oil sector's contribution to GDP will decrease by 9.7 per cent. As a result, Kazakhstan's GDP is projected to be negative by $1.8-4 \%$ [4].

Many experts point to another major factor that has a huge impact on socio-economic stability. This applies to the regional labour market, or rather to its imbalance. As a result of restrictive quarantine measures, we cannot count on active and regulated labour movement in this market. Thus, there is another significant reason for the decline in income and employment.

Based on expert estimates and analytical forecasts, the global economic decline in 2020 will be in the range of 3-5 per cent of the 2019 level [8]. The issue of state support for business is more acute than ever.

The priority measures for such support are shown in Figure 2.

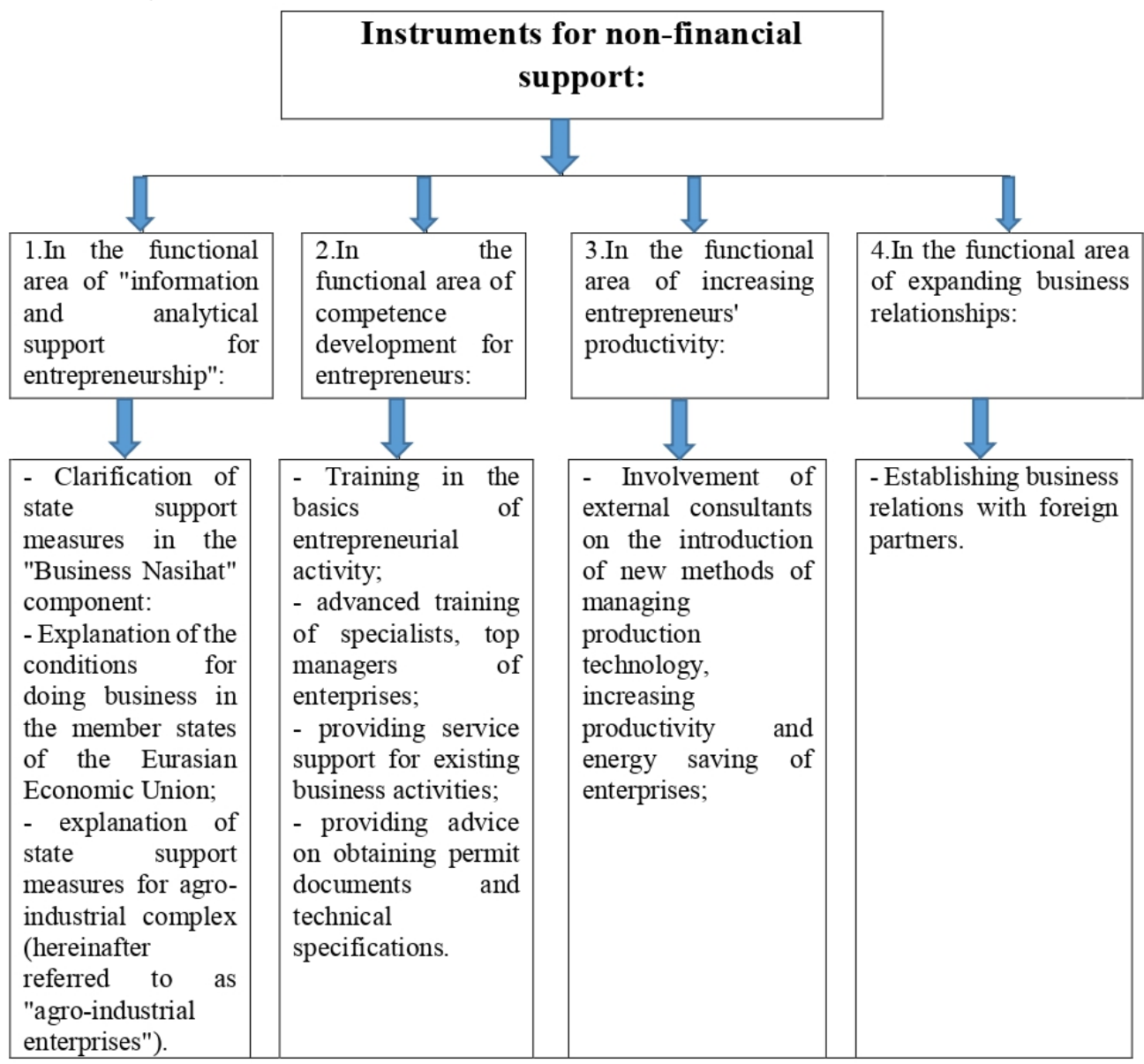

Figure 2 Government support measures for business during the pandemics 
As can be seen from the analysis of the pandemic impact of the economy, the so-called high impact sectors of society: trade, services, and transport are the most heavily affected. It is they who are now suffering significant losses. The International Labour Organisation (ILO) forecasts that nearly 25 million people around the world could lose their jobs because of the new coronavirus pandemic. [9].

These are the industries where the absolute dominance of small and medium-sized businesses is practically present. The continuation and possibility of further recovery in these areas of small and medium-sized businesses will have an adequate impact on consumption levels with all the resulting objective consequences for the economy.

The spread of infection and the worsening of the pandemic have significantly changed modern business. The first thing we see is a change in the professional structure of the business's human resources, namely a change in the professions in demand. Many other professions are no longer in demand. In our view, understanding the specifics of personnel management in an epidemic environment is of paramount importance. To solve this problem, we need to build several business strategies during the pandemic.

The feature of such business strategies is that they provide an opportunity to prepare for business recovery in previous forms and volumes.

Table 1 Business Strategy during the Pandemic

\begin{tabular}{|l|l|l|}
\hline \multicolumn{1}{|c|}{$\begin{array}{c}\text { Name of } \\
\text { business } \\
\text { strategy }\end{array}$} & \multicolumn{1}{|c|}{ Causes } & \multicolumn{1}{|c|}{ Effects } \\
\hline $\begin{array}{l}\text { Reduced } \\
\text { number of } \\
\text { working days or } \\
\text { working hours }\end{array}$ & $\begin{array}{l}\text { almost 25 million } \\
\text { people may lose } \\
\text { their jobs worldwide } \\
\text { (International } \\
\text { Labour Organisation } \\
\text { forecast) }\end{array}$ & $\begin{array}{l}\text { minimising the } \\
\text { loss of } \\
\text { professional } \\
\text { staff, which is } \\
\text { the most } \\
\text { important } \\
\text { resource for } \\
\text { business }\end{array}$ \\
\hline $\begin{array}{l}\text { Transferring } \\
\text { part of } \\
\text { employees to a } \\
\text { business in need } \\
\text { of personnel } \\
\text { (share } \\
\text { personnel) }\end{array}$ & $\begin{array}{l}\text { outflow of } \\
\text { consumers from one } \\
\text { business and an } \\
\text { acute shortage of } \\
\text { labour from another }\end{array}$ & $\begin{array}{l}\text { employment of } \\
\text { released } \\
\text { personnel }\end{array}$ \\
\hline $\begin{array}{l}\text { Reassignment } \\
\text { of business }\end{array}$ & $\begin{array}{l}\text { idle capacity and } \\
\text { downtime of } \\
\text { employees of } \\
\text { companies whose } \\
\text { demand for products } \\
\text { and services has } \\
\text { fallen or has } \\
\text { completely } \\
\text { disappeared }\end{array}$ & $\begin{array}{l}\text { production of } \\
\text { products that } \\
\text { were relevant } \\
\text { puring the }\end{array}$ \\
pandemics
\end{tabular}

Of course, the pandemic will make major adjustments to the condition and functioning of small and medium-sized businesses, which will lead to the closure of some companies, their reorientation, and perhaps the pandemic will give a boost to new development and growth. We believe that this depends directly on whether the business is capable of operating in an environment of rapid digital transformation and what business strategy they would prefer.

\section{CONCLUSION}

1. The fact that the pandemic was the main cause of the crisis has a major impact on the analysis of the consequences, the nature, and the main definition of the means of response.

2. The so-called high-profile business and social sectors, i.e. trade, services, and transport are the most vulnerable to negative consequences. They are the ones who are now suffering the most significant losses.

3. The primary state support measures are focused on the use of non-financial instruments, which is caused by the negative impact of the crisis on the state budget.

4. The priority of preserving and enabling the further recovery of these areas of small and medium-sized businesses has been justified, which will have an adequate impact on consumption levels.

5. Several business strategies have been proposed for the solution of this problem during the pandemic. The peculiarity of such business strategies is that they provide an opportunity to prepare for the recovery of business in its previous form and scope.

\section{REFERENCES}

[1] RIA Novosti (RIA News) (2020). Experts presented the impact of the coronavirus on the world economy, Electronic resource

[2] Kapital (The Capital) (2020). How has the coronavirus pandemic affected the economy of Kazakhstan and what to do with it? Electronic resource.

[3] Soldatova, S. S. (2020) Economic Consequences of the Pandemic COVID-19 for Russia. Scientific and Educational Journal for Students and Teachers STUDENT, 2020, no. 2, pp 260-263.

[4] Vlast (The power), (2020). The economy of the coronavirus times, Electronic resource.

[5] Kapital (The Capital) (2020). EDB forecasts a $1 \%$ decline in Kazakhstan's GDP in 2020, Electronic resource, 22nd April 2020.

[6] World Bank (2020). Economic Report on Kazakhstan: Overcoming the Crisis, Electronic resource, 22nd July 2020. 
[7] National Bank of Kazakhstan (2020), Overview of inflation. June 2020, Electronic resource, June 2020.

[8] The RBC (Ros Biznes Consulting) (2020) Analysts evaluated the damage to the economy from the coronavirus, Electronic resource, 4th June 2020.

[9] Kumpel, A. What strategies will help keep business in the midst of the epidemic. The economics of education. Innovations (2020), Electronic resource. 